\title{
Reduction in Microsegregation in Al-Cu Alloy by Alternating Magnetic Field
}

\author{
Sheng-Ya He ${ }^{1,2}$. Chuan-Jun $\mathrm{Li}^{1}$ · Tong-Jun Zhan ${ }^{1}$ · Wei-Dong Xuan ${ }^{1}$. Jiang Wang ${ }^{1}$ - Zhong-Ming Ren ${ }^{1}$
}

Received: 13 March 2019 / Revised: 16 June 2019 / Published online: 11 July 2019

(c) The Chinese Society for Metals (CSM) and Springer-Verlag GmbH Germany, part of Springer Nature 2019

\begin{abstract}
The microsegregation behavior of the Al-4.5 wt\% Cu alloy solidified at different cooling rates under the alternating magnetic field (AMF) was investigated. The experimental results showed that the amount of non-equilibrium eutectics in the interdendritic region decreased upon applying the AMF at the same cooling rate. The change in microsegregation could be explained quantificationally by the modifications of dendritic coarsening, solid-state back diffusion and convection in the AMF. The enhanced diffusivity in the solid owing to the AMF was beneficial for the improvement in microsegregation compared to the cases without an AMF. In contrast, the enhanced dendritic coarsening and forced convection in the AMF were found to aggravate the microsegregation level. Considering the contributions of the changes in above factors, an increase in solid diffusivity was found to be primarily responsible for the reduced microsegregation in the AMF. In addition, the microsegregation in the AMF was modeled using the analytical model developed by Voller. The calculated and experimental results were in reasonable agreement.
\end{abstract}

Keywords Microsegregation $\cdot$ Solidification $\cdot$ Alternating magnetic field $\cdot$ Diffusion $\cdot$ Coarsening $\cdot$ Convection

\section{Introduction}

The microsegregation, which refers to the chemical inhomogeneity over a dendritic scale, significantly affects the mechanical properties of alloys [1]. Controlling microsegregation is of practical significance especially during the alloy solidification so that the time for subsequent homogenization heat treatment can be reduced effectively. Up to date, plenty of methods, such as gravity-free solidification technique [2], addition of specific elements [3] and rapid solidification technique $[4,5]$, have been developed to modify microsegregation formation. Nevertheless, these methods still

Available online at http://link.springer.com/journal/40195

Chuan-Jun Li

chuanjunli21@sina.com

Jiang Wang

jiangwang@i.shu.edu.cn

1 State Key Laboratory of Advanced Special Steel and School of Materials Science and Engineering, Shanghai University, Shanghai 200444, China

2 Helmholtz-Zentrum Dresden-Rossendorf (HZDR), 01328 Dresden, Germany have many defects. For instance, (1) the sample is confined to small volume during the gravity-free solidification; (2) additional elements may result in the formation of harmful impurities; (3) the cooling rates during practical casting of large size samples are relatively slow and thus the rapid solidification technique generally is limited.

Over the past decades, the utilization of magnetic fields used to materials processing has attracted extensive attention owing to its various effects, such as enhanced undercooling [6,7], field-modified convection $[8,9]$ and solute/ phase migration $[10,11]$. Thereinto, several publications have reported that the alternating magnetic field (AMF) is able to modify microsegregation during alloys solidification [12-16]. These studies demonstrate that the application of an AMF during alloys solidification provides a promising way to get high-quality casting. However, they did not associate the change in microsegregation with various factors influencing microsegregation, such as solid-state back diffusion, dendritic coarsening, force convection [17-21]. This means that physical nature of the change in microsegregation in the AMF is still an open question. It is predictable that one or more of those factors influencing microsegregation probably vary in an AMF, which will further modify the microsegregation formation. Thus, it is necessary to quantify the effect 
of the changes in various factors on microsegregation formation during alloys solidification under the action of the AMF.

In this work, a series of experiments were designed to observe the microsegregation behavior of solidified Al-4.5 wt $\% \mathrm{Cu}$ alloy in an AMF. The variations of the factors affecting microsegregation were evaluated quantitatively. Further, the microsegregation level in the AMF was calculated using the modified Voller model [22].

\section{Experimental}

The Al-4.5 wt $\% \mathrm{Cu}$ alloy was prepared by melting highpurity metals $\mathrm{Al}(99.999 \%)$ and $\mathrm{Cu}(99.999 \%)$ in a vacuum induction furnace. The master alloy was remelted three times and then suctioned into a quartz tube by vacuum suction casting apparatus to obtain cylinder samples with a dimension of $6 \mathrm{~mm}$ in diameter and $10 \mathrm{~mm}$ in length. The sample was enveloped into a graphite crucible for use.

The AMF with a continuously adjustable intensity up to $0.1 \mathrm{~T}$ was generated by water-cooling copper coils together with a $50 \mathrm{~Hz}$ alternating current (AC) power source. It is worth noting that the eddy current heating induced by the AMF can cause a rise in the temperature of the samples. Therefore, the temperature of the sample in the resistance furnace was carefully checked. It was found that the application of $0.05 \mathrm{~T}$ and $0.1 \mathrm{~T}$ AMF would lead to an additional temperature of about $2{ }^{\circ} \mathrm{C}$ during the solidification in comparison with those without the AMF. In order to ensure that all the samples were solidified at same temperature condition, the temperature controller was calibrated using a standard pure $\mathrm{Al}$ (99.999\%) sample under the AMF. Before the experiments, the sample was enclosed in the quartz pipe and evacuated to $10^{-3} \mathrm{~Pa}$ to avoid oxidation. Afterward, the sample was placed in the central region with maximum AMF intensity. Each sample was heated to $750{ }^{\circ} \mathrm{C}$ at the heating rate of $10{ }^{\circ} \mathrm{C} \mathrm{min}{ }^{-1}$, holding for $30 \mathrm{~min}$ and then cooled to room temperature at various cooling rates $\left(1^{\circ} \mathrm{C} \mathrm{min}^{-1}\right.$, $5{ }^{\circ} \mathrm{C} \min ^{-1}$ and $15{ }^{\circ} \mathrm{C} \min ^{-1}$ ). The sample temperatures were monitored using K-type thermocouples with an accuracy of $\pm 1{ }^{\circ} \mathrm{C}$. The experimental apparatus is schematically shown in Fig. 1.

After grounded and polished, the microstructures of the solidified samples were observed by scanning electron microscope (SEM). More than 30 secondary dendrites on each sample were measured to obtain the average secondary dendritic arm spacing (SDAS). The amount of non-equilibrium eutectics, which was used to characterize microsegregation level, was obtained using image software Image J. To calculate effective partition coefficient $k_{\mathrm{e}}$, the composition of $\mathrm{Cu}$ element on the transverse section was measured using the energy dispersive spectrometer (EDS) equipped on the SEM. The point matrix approach proposed by Gungor [23] was used to sort the raw data from the microprobe analysis. In the center of sample, an area of $1000 \mu \mathrm{m} \times 1000 \mu \mathrm{m}$ containing 400 points with equal interval was selected to carry out the composition measurement. The details of sorting data were given as follows: all measured data were sorted to monotonically increase $\left(k_{0}<1, k_{0}\right.$ is the equilibrium partition coefficient); then, each ordered data point $i$ was assigned a corresponding rank number $R_{i}$, ranging from 1 to 400 . Eventually, the fraction solid for each point could be obtained by $f_{\mathrm{s}}(i)=\left(R_{i}-0.5\right) / 400$. The value of $k_{\mathrm{e}}$ could be calculated by linear fitting Scheil equation [24].

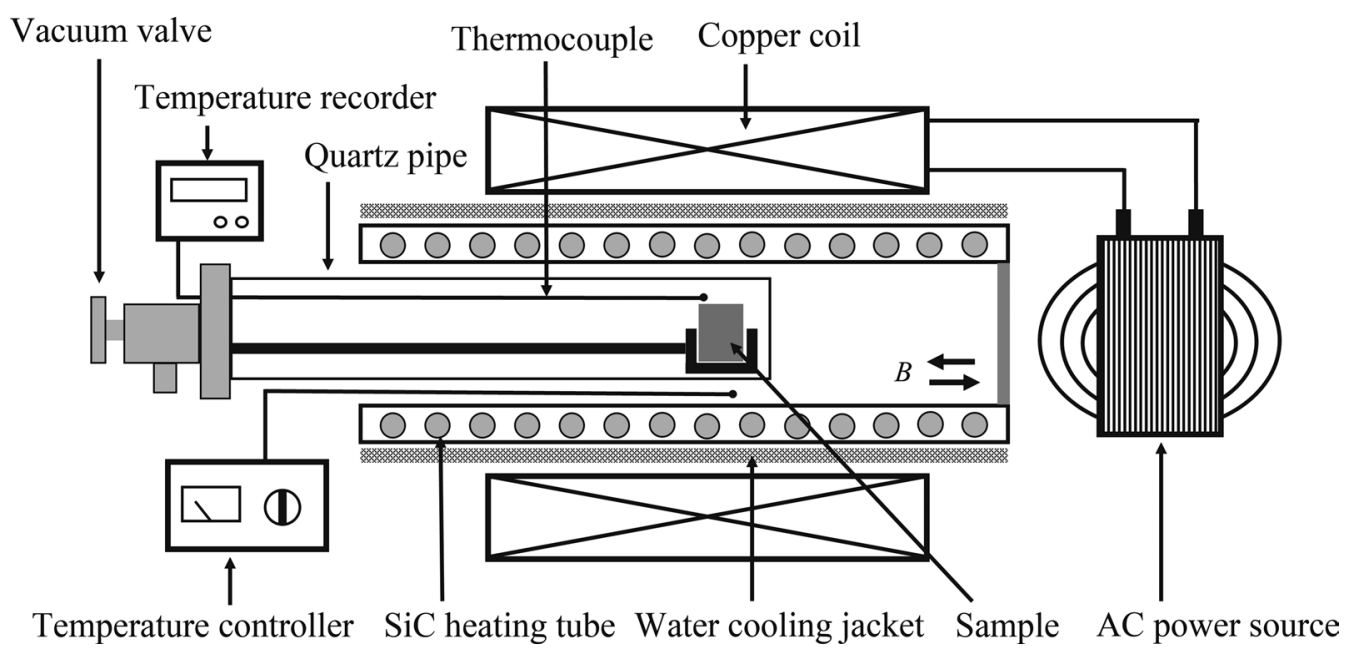

Fig. 1 Schematic diagram of experimental apparatus for alloy solidification in an AMF 


\section{Theoretical modeling}

The analytical model proposed by Voller [22] is utilized to predict the microsegregation level. The domain of microsegregation analysis is a one-dimensional (1D) half-secondary arm space, as shown in Fig. 2. The model incorporates solid-state back diffusion and dendritic coarsening. Reasonable assumptions are made as follows: (1) local equilibrium is maintained at the liquid-solid interface; (2) the liquid phase is completely uniform at any time, but the solute concentration is changed with time; (3) the liquidus and solidus are assumed to be straight; (4) the temperature $T$ is uniform owing to the fast heat diffusion rate; (5) all complicated curvatures and end effects are negligible.

As the solidification proceeds, the total mass in the volume element must be conserved, which can be established as:

$\int_{0}^{L_{\mathrm{s}}} C_{\mathrm{s}} \mathrm{d} x+\left(L_{0}-L_{\mathrm{s}}\right) C_{L}=L_{0} C_{0}$,

where $L_{0}, L_{\mathrm{s}}, C_{\mathrm{s}}, C_{\mathrm{L}}, C_{0}$ denote the length of half-arm spacing, the length of solid phase, the solid composition, the liquid composition and the original composition, respectively. Equation (1) can be rewritten to the differential form with respect to time $t$ :

$\int_{0}^{L_{\mathrm{s}}} \frac{\partial C_{\mathrm{s}}}{\partial t} \mathrm{~d} x+\left(k_{0}-1\right) C_{L} \frac{\mathrm{d} L_{\mathrm{s}}}{\mathrm{d} t}+\left(L_{0}-L_{\mathrm{s}}\right) \frac{\mathrm{d} C_{L}}{\mathrm{~d} t}+\left(C_{L}-C_{0}\right) \frac{\mathrm{d} L_{0}}{\mathrm{~d} t}=0$.

Coarsening process can be expressed as:

$\lambda=2 L_{0}=M t_{\mathrm{f}}^{1 / 3}$ where $\lambda$ is the SDAS, $M$ is the coarsening coefficient, $t_{\mathrm{f}}$ is the local solidification time. The back diffusion in the solid obeys Fick's second law:

$\frac{\partial C_{\mathrm{s}}}{\partial t}=\alpha \frac{\partial^{2} C_{\mathrm{s}}}{\partial x^{2}}$

where $\alpha$ is the Fourier number, defined as $\alpha=4 D_{\mathrm{s}} t_{\mathrm{f}} / \lambda^{2}$, in which $D_{\mathrm{s}}$ is the solid diffusion coefficient. This Fourier number provides the dimensionless control parameter to estimate the amount of solid-state diffusion within the volume element.

Substituting Eq. (4) into Eq. (2) and expanding the integral, it gives:

$\left.\alpha \frac{\partial C_{\mathrm{s}}}{\partial x}\right|_{x=L_{\mathrm{s}}}+\left(k_{0}-1\right) C_{\mathrm{L}} \frac{\mathrm{d} L_{\mathrm{s}}}{\mathrm{d} t}+\left(L_{0}-L_{\mathrm{s}}\right) \frac{\mathrm{d} C_{L}}{\mathrm{~d} t}+\left(C_{\mathrm{L}}-C_{0}\right) \frac{\mathrm{d} L_{0}}{\mathrm{~d} t}=0$.

Using the initial conditions: $L_{\mathrm{s}}=0, C_{\mathrm{L}}=C_{0}$, and $\partial C_{\mathrm{s}} /\left.\partial x\right|_{x=0}=0$, Eq. (5) can be solved with a time-marching numerical solution. Then, the amount of non-equilibrium eutectics is able to be obtained with a given eutectic concentration $C_{\text {eut }}$. The details can be referred to Ref. [22].

\section{Results and Discussion}

Figure $3 \mathrm{a}-\mathrm{c}$ shows the backscattered electron (BSE) images of the $\mathrm{Al}-4.5 \mathrm{wt} \% \mathrm{Cu}$ samples solidified at the cooling rate of $15{ }^{\circ} \mathrm{C} \mathrm{min}{ }^{-1}$ with and without the AMFs. It can be seen that the microstructure consists of the primary $\alpha$-Al phase (dark part) and non-equilibrium eutectics (bright part). The magnified image clearly shows $\mathrm{Al}-\mathrm{Al}_{2} \mathrm{Cu}$ lamellar structures

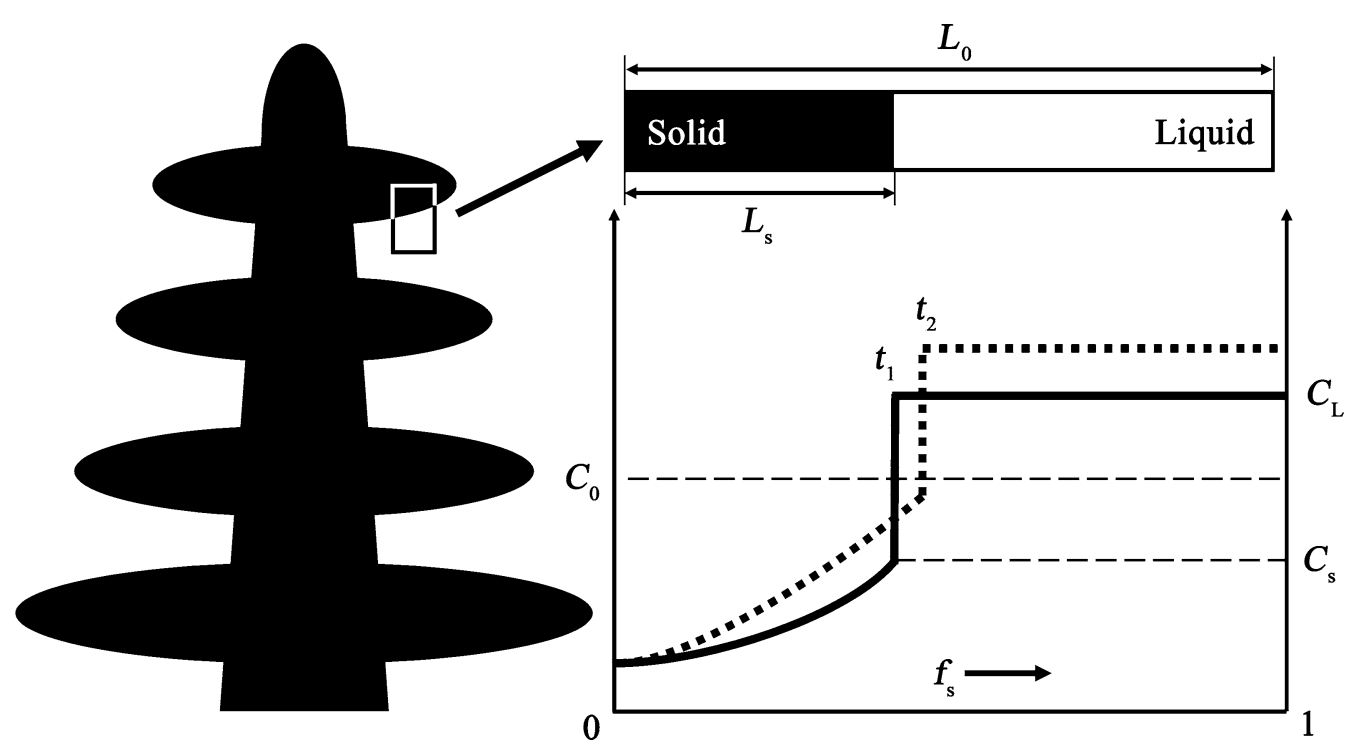

Fig. 2 One-dimensional domain for microsegregation model 

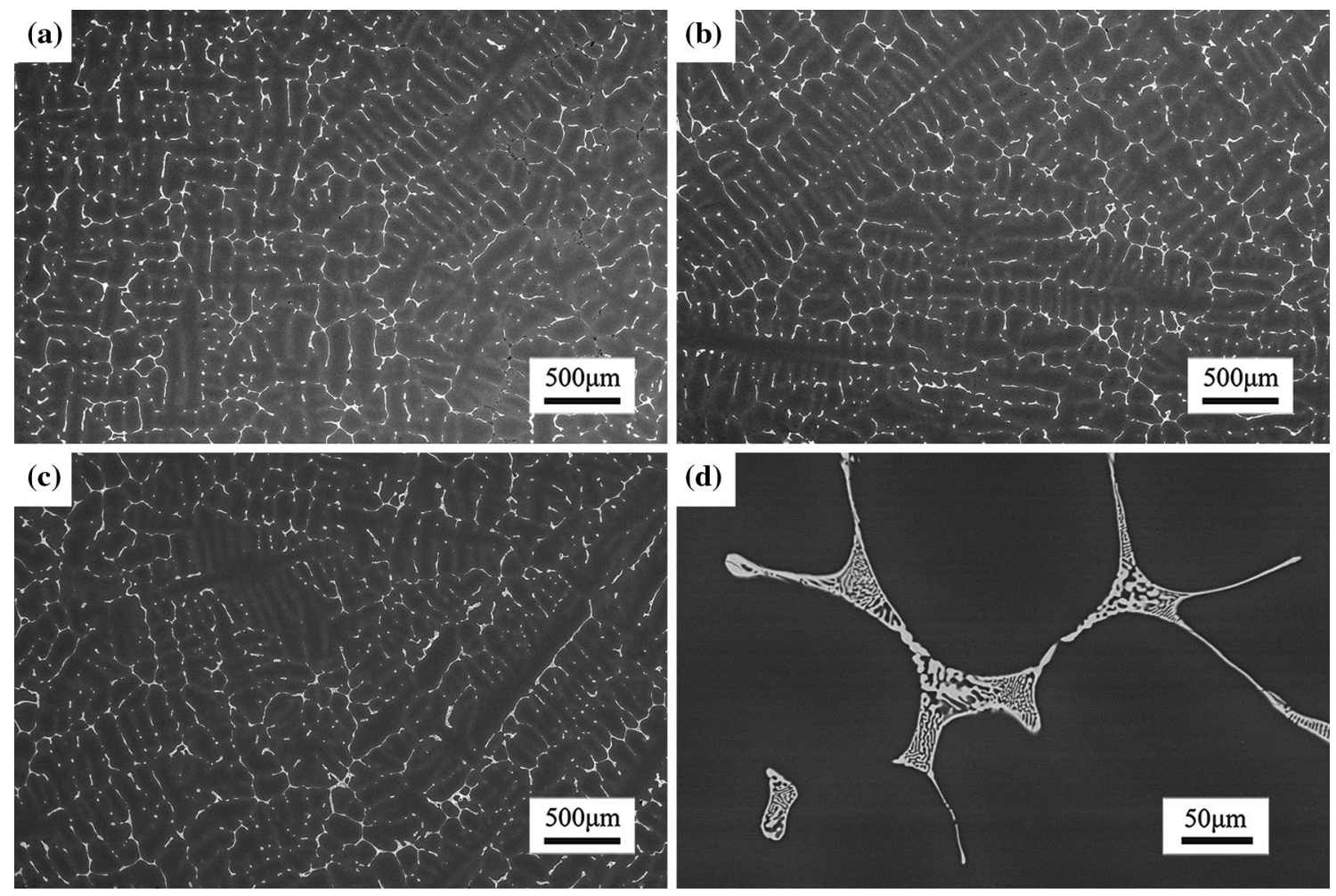

Fig. 3 Morphologies of Al-4.5 wt $\% \mathrm{Cu}$ alloy solidified at the cooling rate of $15{ }^{\circ} \mathrm{C} \min ^{-1}$ with different AMF intensities: a 0 T; b $0.05 \mathrm{~T}$; $\mathbf{c} 0.1 \mathrm{~T}$; d non-equilibrium lamellar eutectics under $0.1 \mathrm{~T}$

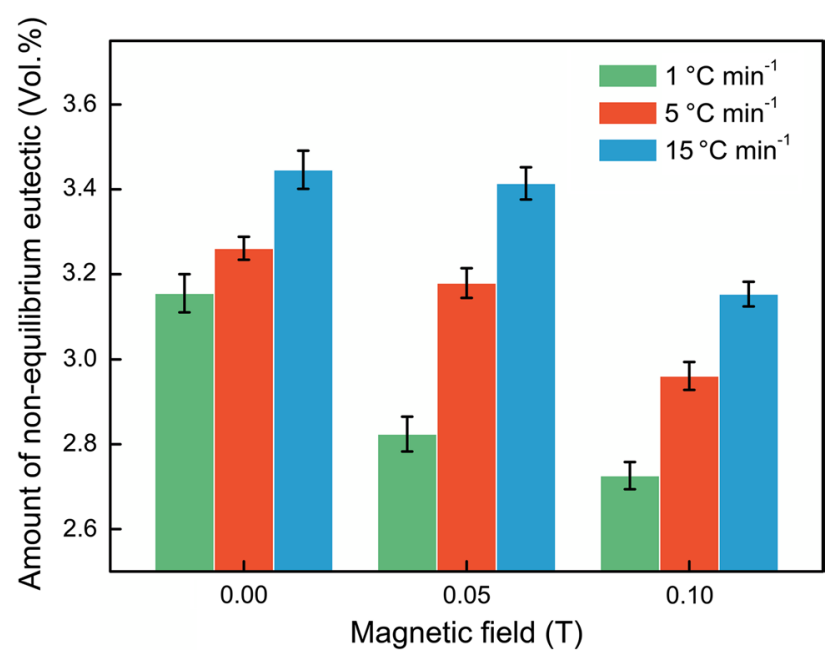

Fig. 4 Amount of non-equilibrium eutectics in the solidified Al-4.5 wt $\% \mathrm{Cu}$ alloy at various cooling rates with and without AMFs

(Fig. 3d). Figure 4 shows the amount of non-equilibrium eutectics at various cooling rates with and without the AMFs. Obviously, the amount of non-equilibrium eutectics decreases under the action of the AMF at the same cooling rate. For the same AMF intensity, the amount of non-equilibrium eutectics increases with increasing the cooling rate, which is still in accordance with variation tendency in the normal solidification conditions. Thus, it can be concluded that the application of an AMF reduces the microsegregation level. The experimental observation here is in coincidence with previous studies. For example, the decreased microsegregation has also been found in 7075 aluminum alloy produced by low-frequency electromagnetic casting [14] and directionally solidified $\mathrm{Ga}-\mathrm{In}-\mathrm{Sb}$ alloys under a $3 \mathrm{mT}$ AMF $[12,13]$.

It has been well established that multiple factors, such as coarsening kinetics, solid-state back diffusion, melt convection and shift of solidus/liquidus, contribute to microsegregation formation [21, 25-27]. Thus, the change in microsegregation in the AMF may be attributed to the change in one or more above factors. The contributions of various factors in an AMF to microsegregation will be discussed below.

Firstly, it has been demonstrated that the dendritic coarsening can affect the formation of microsegregation [28]. Mortensen [29] pointed out that the dendritic coarsening might increase the average solid concentration by remelting the smaller dendritic arms. However, it is paradoxical that a large SDAS enlarges the path of solid-state back diffusion, which is adverse to solute homogenization. Figure 5a depicts the plot of the average SDAS versus cubic root of solidification time. The experimental results show that the 
(a)

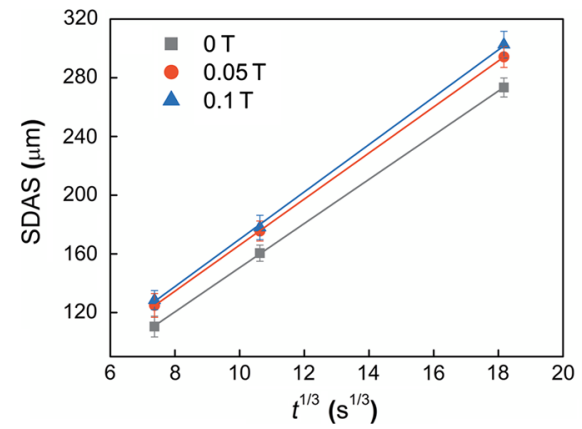

(b)

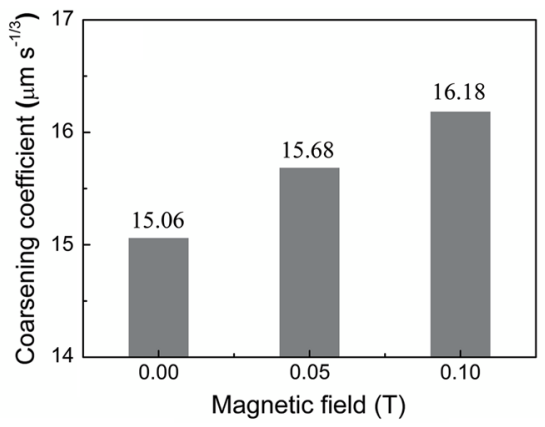

(c)

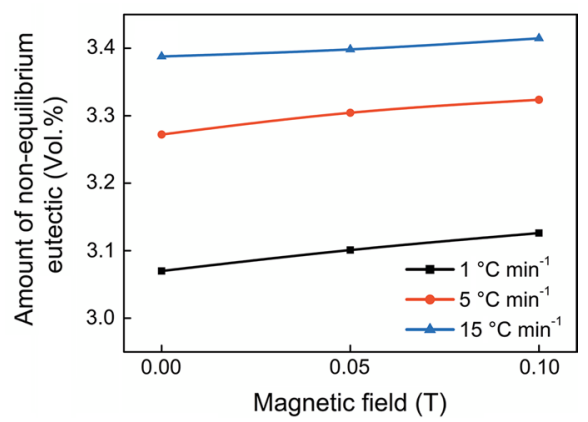

Fig. 5 a SDAS plotted against the cubic root of solidification time, $\mathbf{b}$ coarsening coefficient in different AMF intensities and $\mathbf{c}$ amount of non-equilibrium eutectics calculated using measured coarsening coefficients. The following values are used for calculations: $k_{0}=0.14$, $C_{\text {eut }}=33.2 \mathrm{wt} \%[33], D_{\mathrm{s}}=2.04 \times 10^{-5} \exp (-15336 / T) \mathrm{m}^{2} \mathrm{~s}^{-1}[34]$

average SDAS increases upon applying an AMF. The relationship between SDAS and solidification time holds cubic law (Eq. 3) regardless of the presence of the AMF, from which the coarsening coefficient can be calculated by linear fitting the plot, as indicated in Fig. 5b. The coarsening coefficient slightly increases with increasing the AMF intensity. Thus, the AMF results in a faster coarsening rate. According to Kirkwood's model [30], coarsening coefficient can be expressed as:

$M=\left(-\frac{128 \sigma D T_{m} \ln \left(C_{\mathrm{eut}} / C_{0}\right)}{Q m\left(1-k_{0}\right)\left(C_{\mathrm{eut}}-C_{0}\right)}\right)^{1 / 3}$

where $D$ is the liquid diffusivity, $\sigma$ is the liquid-solid interface tension, $T_{\mathrm{m}}$ is the melting point, $Q$ is the heat of fusion and $m$ is the liquidus slope. It has been found that the $\mathrm{Al}-\mathrm{Cu}$ alloy phase diagram is not affected by the magnetic field, thus the parameters such as $T_{\mathrm{m}}, Q, m, C_{\text {eut }}$ and $C_{0}$ will be constant in the AMF [31]. Also, Sun et al. [32] found that the additional liquid-solid interface tension induced by the magnetic field in $\mathrm{Al}-\mathrm{Cu}$ alloys could be ignored. Therefore, the enhancement of coarsening coefficient can be possibly attributed to the increase in liquid diffusivity, which is caused by the forced convection in the AMF. Incorporating the coarsening coefficients into the Voller model, the calculated results suggest that the microsegregation increases with increasing coarsening coefficient (Fig. 5c).

Secondly, the solid-state back diffusion is conducive to the reduction in the microsegregation level during dendritic solidification [33-36]. Several studies showed that the solid diffusivity was enhanced under the action of an AMF. For example, Liu et al. [37-39] investigated the phase growth in the diffusion couples of $\mathrm{Al}-\mathrm{Cu}, \mathrm{Al}-\mathrm{Mg}$ and $\mathrm{Al}-\mathrm{Zn}$ under an AMF and found that the AMF promoted the growth of the intermediate phases. In our previous work, it was found that the AMF significantly enhanced the solid diffusion coefficients in $\mathrm{Ni}-\mathrm{Al}$ and $\mathrm{Ni}-\mathrm{Cr}$ alloys. Based on the magnetoplastic effect (MPE), a quantitative relation between the AMF intensity and the solid diffusion coefficient is deduced [40, 41]:

$D_{\text {eff }}(H)=D_{\text {eff }}(0) \cdot\left(1+A \cdot \frac{H^{2}}{H_{0}^{2}}\right)$,

$A=\frac{\pi r^{2} \rho_{\mathrm{d} 0}\left(\frac{D_{\mathrm{d}}}{D_{\mathrm{L}}}-1\right)}{1+\pi r^{2} \rho_{\mathrm{d} 0}\left(\frac{D_{\mathrm{d}}}{D_{\mathrm{L}}}-1\right)}$,

where $D_{\text {eff }}(H)$ and $D_{\text {eff }}(0)$ refer to the effective diffusion coefficients with and without an AMF, $H$ is the AMF intensity, $H_{0}$ is the characteristic magnetic field inducing depinning of dislocations from paramagnetic centers, $A$ is the proportionality constant that is related to $\rho_{\mathrm{d} 0}, r, D_{\mathrm{d}}, D_{\mathrm{L}}$ which denote the dislocation density without an AMF, the radius of the dislocation pipe, the dislocation diffusion coefficient and the lattice diffusion coefficient, respectively. Since the dislocation density of as-cast alloys is between that of annealed alloys and deformed alloys, it is reasonable to assume the magnitude of dislocation density without an AMF is about $10^{13} \mathrm{~m}^{-2}$ in this work [42]. The effective diffusion coefficient with an AMF can be estimated using Eqs. (7) and (8), shown in Fig. 6a. It reveals that the solid diffusion coefficient increases remarkably with increasing AMF intensity. Considering the change in solid diffusivity under an AMF into Voller model, it can be seen that the enhancement of solid-state back diffusion is beneficial for further reducing microsegregation (Fig. 6b).

Thirdly, forced convection will lead to the acceleration of mass transport in the melt and thus influence the effective partition coefficient to some extent [14, 24]. It is well known that there exists a forced convection generated by the interaction between induced currents and the AMF. The fieldinduced convection improves the mixing of rejected solute 

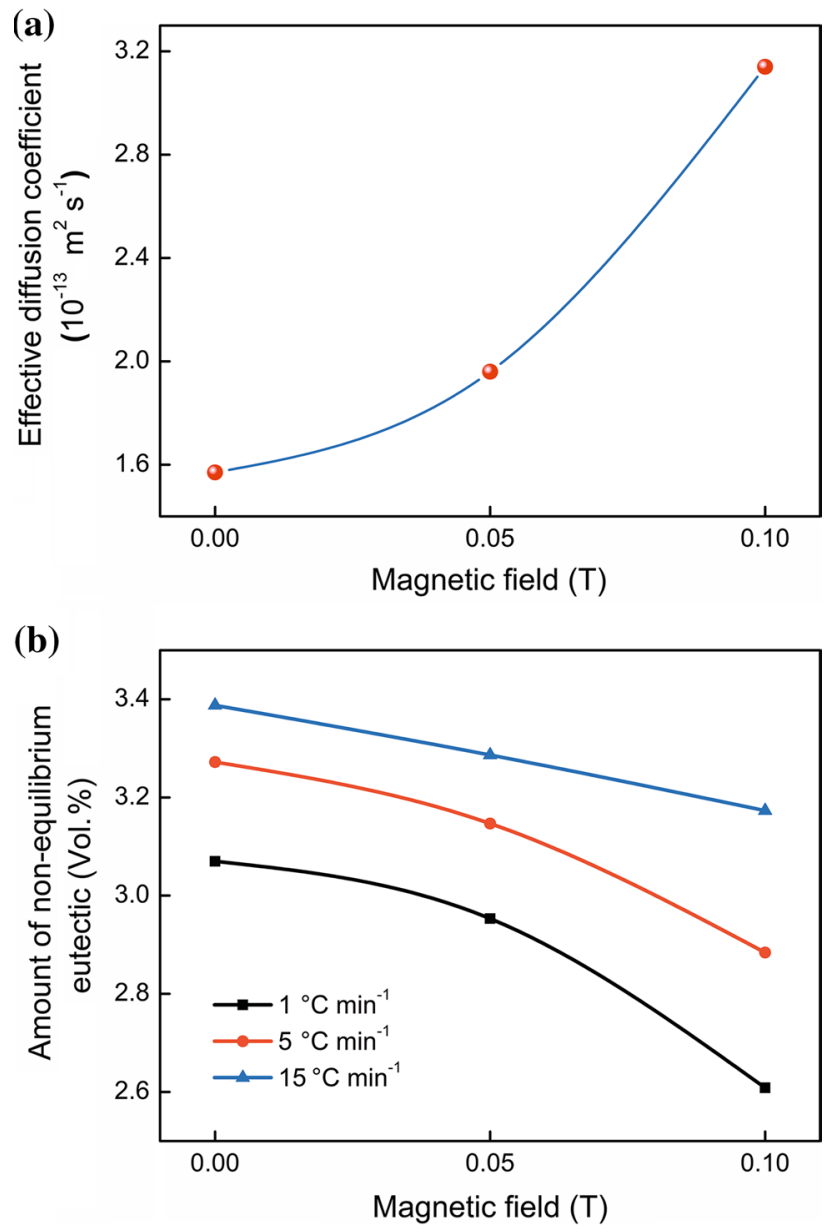

Fig. 6 a Calculative effective solid diffusion coefficient at $548{ }^{\circ} \mathrm{C}$ in AMFs. The following parameters are used: $\rho_{\mathrm{d} 0}=10^{13} \mathrm{~m}^{-2}, H_{0}=0.1 \mathrm{~T}$ [43], $r=0.5 \mathrm{~nm}$ [44], $D_{\text {eff }}(0)=2.04 \times 10^{-5} \exp (-15336 / T) \mathrm{m}^{2} \mathrm{~s}^{-1}$ [34], $D_{\mathrm{d}}=1.71 \times 10^{-4} \exp (-9780.8 / T) \mathrm{m}^{2} \mathrm{~s}^{-1}$ [44], $D_{\mathrm{L}}=2 \times 10^{-6}$ $\exp (-17159.4 / T) \mathrm{m}^{2} \mathrm{~s}^{-1}$ [45]; b calculated amount of non-equilibrium eutectics in consideration of the change in solid diffusivity in the AMF

in the melt [46-48]. Here, the effective partition coefficient is evaluated by the modified Scheil equation [24]:

$C_{\mathrm{s}}=k_{\mathrm{e}} C_{0}\left(1-f_{\mathrm{s}}\right)^{k_{\mathrm{e}}-1}$.

Taking the logarithm, Eq. (9) becomes:

$\ln \left(C_{\mathrm{s}} / C_{0}\right)=\left(k_{\mathrm{e}}-1\right) \ln \left(1-f_{\mathrm{s}}\right)+\ln k_{\mathrm{e}}$.

Using the measured data of $\mathrm{Cu}$ composition, a logarithmic plot of $\ln \left(C_{\mathrm{s}} / C_{0}\right)$ against $\ln \left(1-f_{\mathrm{s}}\right)$ can be obtained. The value of $k_{\mathrm{e}}$ can be calculated from the slope $\left(k_{\mathrm{e}}-1\right)$, as shown in Fig. 7a. The effective partition coefficient decreases with an increase in AMF intensity, which is contrary to the observations in references $[14,16]$. In this work, the forced convection induced by the AMF will result in the enhancement of liquid diffusivity and decrease in diffusion layer thickness, which is probably responsible for the decrease in
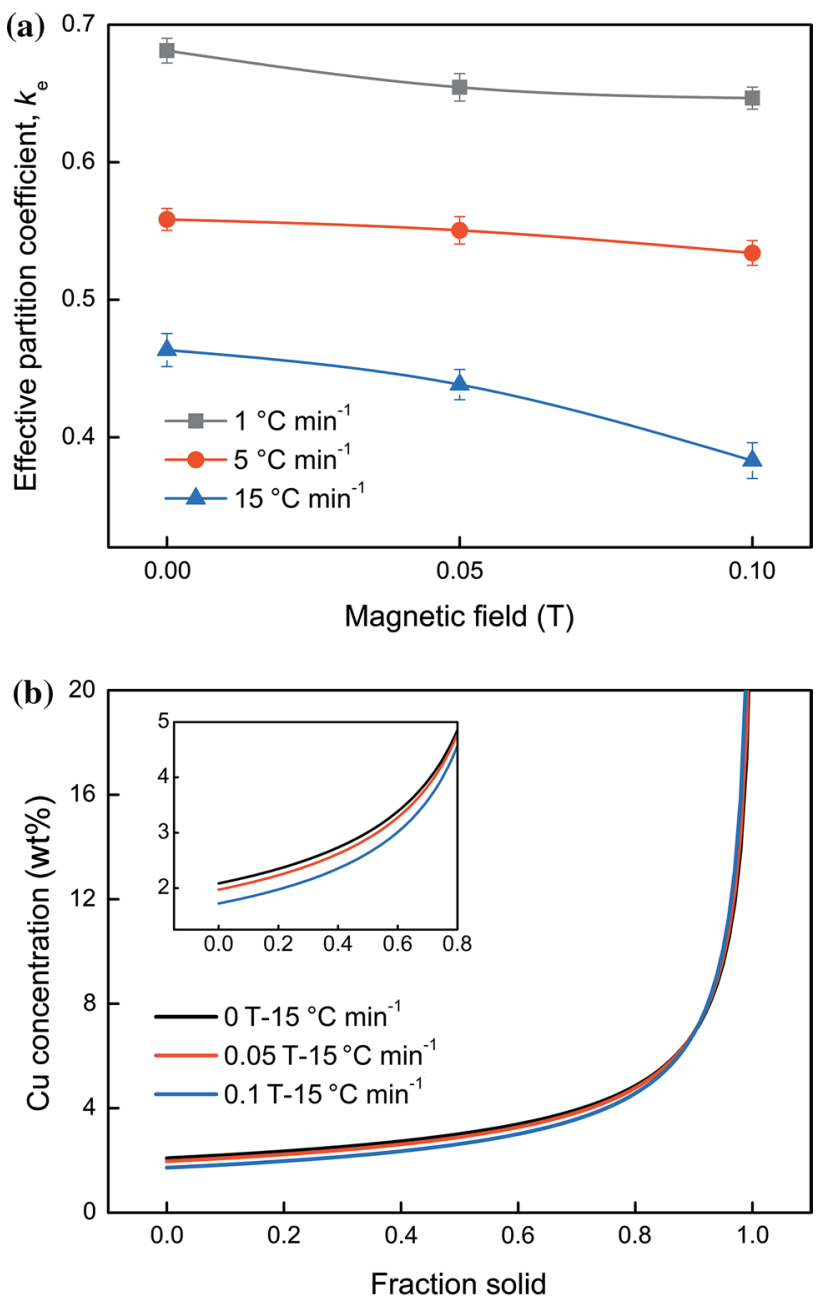

Fig. 7 a Effective partition coefficients at different cooling rates with different AMFs, $\mathbf{b}$ concentration versus fraction solid profiles at the cooling rate of $15^{\circ} \mathrm{C} \mathrm{min}-1$ with different AMFs

$k_{\mathrm{e}}$ [24]. Due to the limitation of mathematical algorithm in Voller model, the effect of the change in $k_{\mathrm{e}}$ on microsegregation is analyzed by classical Brody-Flemings model with the replacement of $k_{0}$ with $k_{\mathrm{e}}$ [35]:

$C_{\mathrm{s}}=k_{\mathrm{e}} C_{0}\left(1-\frac{f_{\mathrm{s}}}{1+k_{\mathrm{e}} \alpha}\right)^{k_{\mathrm{e}}-1}$

Figure $7 \mathrm{~b}$ presents the concentration versus fraction solid profiles with different AMF intensities at the cooling rate of $15{ }^{\circ} \mathrm{C} \mathrm{min}{ }^{-1}$. The curves show that the reduction in $k_{\mathrm{e}}$ results in the increase in the microsegregation level. However, the difference among the curves is inconspicuous (the maximum is $0.36 \%$ ). It is concluded that the effect of change in convection in the AMF on microsegregation is ignorable.

Above analysis suggests that the factors affecting microsegregation can be modified to different extents under the 
Table 1 Parameters of Al-4.5 wt\%Cu alloy for calculations

\begin{tabular}{llll}
\hline Parameter & $0 \mathrm{~T}$ & $0.05 \mathrm{~T}$ & $0.1 \mathrm{~T}$ \\
\hline$M\left(\mu \mathrm{m} \mathrm{s}^{-1 / 3}\right)$ & 15.06 & 15.68 & 16.18 \\
$D_{\mathrm{s}}\left(\mathrm{m}^{2} \mathrm{~s}^{-1}\right)^{\mathrm{a}}$ & $1.57 \times 10^{-13}[34]$ & $1.96 \times 10^{-13}$ & $3.14 \times 10^{-13}$ \\
\hline
\end{tabular}

${ }^{\text {a }}$ The solid diffusion coefficient at $548{ }^{\circ} \mathrm{C}$ is used for calculations owing to the limit of Voller model

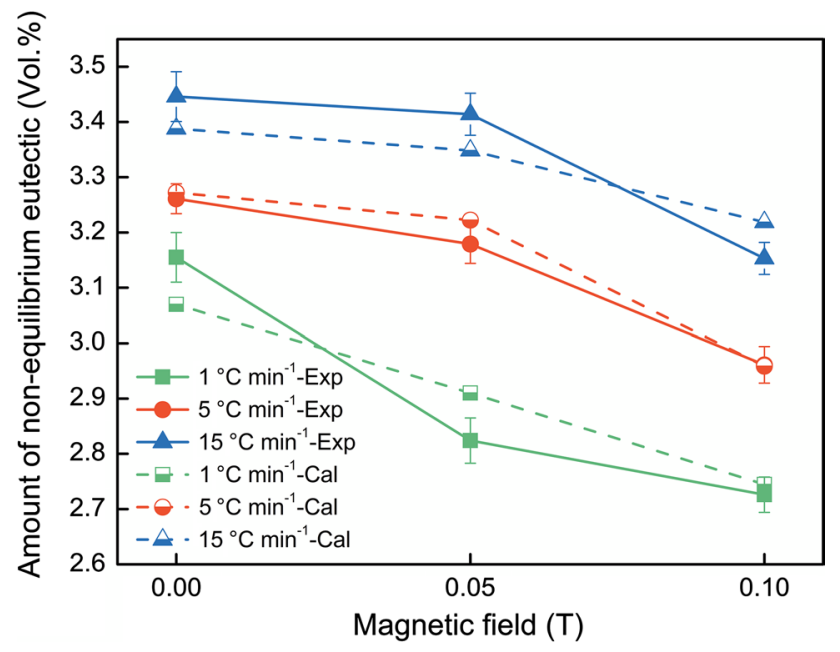

Fig. 8 Calculated and experimental results of amount of non-equilibrium eutectics with and without AMFs

action of an AMF. The Voller model is appropriate for prediction of the microsegregation under an AMF considering the changes in the above factors. Moreover, modifications of parameters are made: (1) the coarsening process is accelerated by the AMF, the measured coarsening coefficients are adopted; (2) the model based on MPE theory is applied to calculate the solid-state diffusion coefficient in the AMF, i.e., Eq. (7). The relevant parameters used in the calculations are listed in Table 1. Figure 8 compares calculated and measured amount of non-equilibrium eutectics with and without the AMFs. The calculated results are reasonably in agreement with the experimental results. Since the enhanced dendritic coarsening and forced convection increase microsegregation level, it can be deduced that the decrease in microsegregation under an AMF mainly results from the increase in diffusivity of solid phase.

\section{Conclusion}

The effect of the AMF on microsegregation behavior in the solidified Al-4.5 wt\% Cu alloy was investigated experimentally. It was found that the amount of non-equilibrium eutectics decreased with increasing AMF intensity at the same cooling rate. The changes in factors possibly affecting microsegregation in the AMF, such as dendritic coarsening, solid diffusivity and forced convection, were analyzed. The enhancement of dendritic coarsening and forced convection was found to increase the microsegregation while the increase in diffusion coefficient in the solid phase was beneficial for homogenization. Considering all contributions in the AMF, it was concluded that the alleviation of microsegregation was mainly attributed to the increase in solid diffusion coefficient in the AMF. The Voller model incorporating dendritic coarsening and solidstate back diffusion was used to predict the microsegregation formation in the AMF. The calculated results were in reasonable agreement with the experimental results.

Acknowledgements This work was supported financially by the National Natural Science Foundation of China (Nos. U1560202, 51690162 and 51604171), Shanghai Municipal Science and Technology Commission Grant (No. 17JC1400602), Shanghai Pujiang Program (No. 18PJ1403700), the program of China Scholarships Council (No. 201806890052) and the National Science and Technology Major Project "Aeroengine and Gas Turbine" (No. 2017-VII-0008-0102).

\section{References}

[1] R. Smith, Metall. Mater. Trans. B 49, 6 (2018)

[2] J.T. Yue, F.W. Voltmer, J. Cryst. Growth 29, 3 (1975)

[3] R.M. Kearsey, J.C. Beddoes, K.M. Jaansalu, W.T. Thompson, P. Au, in Superalloy, ed. by K.A. Green, T.M. Pollock, H. Harada, T.E. Howson, R.C. Reed, J.J. Schirra, S. Walston (TMS, Pennsylvania, 2004), p. 801

[4] L. Ling, Y. Han, W. Zhou, H. Gao, D. Shu, J. Wang, M. Kang, B. Sun, Metall. Mater. Trans. A 46, 1 (2015)

[5] M. Paliwal, D.H. Kang, E. Essadiqi, I.H. Jung, Metall. Mater. Trans. A 45, 8 (2014)

[6] R. Guo, C. Li, S. He, J. Wang, W. Xuan, X. Li, Y. Zhong, Z. Ren, Jpn. J. Appl. Phys. 57, 8 (2018)

[7] J. Wang, Y. He, J. Li, C. Li, H. Kou, P. Zhang, E. Beaugnon, Mater. Chem. Phys. 225, 133 (2019)

[8] L. Hou, Y. Dai, Y. Fautrelle, Z. Li, Z. Ren, C. Esling, X. Li, J. Alloys Compd. 758, 25 (2018)

[9] Y. Hou, Z.Q. Zhang, W.D. Xuan, J. Wang, J.B. Yu, Z.M. Ren, Acta Metall. Sin. (Engl. Lett.) 31, 681 (2018)

[10] Q. Wang, T. Liu, K. Wang, P. Gao, Y. Liu, J. He, ISIJ Int. 54, 3 (2014)

[11] J. Wang, X. Lin, Y. Fautrelle, H. Nguyen-Thi, Z. Ren, Metall. Mater. Trans. B 49, 3 (2018)

[12] C. Stelian, Y. Delannoy, Y. Fautrelle, T. Duffar, J. Cryst. Growth 266, 1 (2004)

[13] C. Stelian, Y. Delannoy, Y. Fautrelle, T. Duffar, J. Cryst. Growth 275, 1 (2005)

[14] D. Chen, H. Zhang, H. Jiang, J. Cui, Materialwiss. Werkstofftech. 42, 6 (2011)

[15] C. Li, Y.D. Yu, Mater. Sci. Eng. A 559, 22 (2013)

[16] F. Wang, L. Zhang, A. Deng, X. Xu, E. Wang, Metals 6, 1 (2015)

[17] A. Roósz, E. Halder, H.E. Exner, Mater. Sci. Technol. 1, 12 (1985)

[18] T. Kraft, Y.A. Chang, Metall. Mater. Trans. A 29, 9 (1998)

[19] T. Himemiya, T. Umeda, ISIJ Int. 38, 7 (1998) 
[20] V.R. Voller, J. Cryst. Growth 226, 4 (2001)

[21] A. Noeppel, A. Ciobanas, X.D. Wang, K. Zaidat, N. Mangelinck, O. Budenkova, A. Weiss, G. Zimmermann, Y. Fautrelle, Metall. Mater. Trans. B 41, 1 (2010)

[22] V.R. Voller, Int. J. Heat Mass Transf. 43, 11 (2000)

[23] M.N. Gungor, Metall. Trans. A 20, 11 (1989)

[24] W.V. Youdelis, R.C. Dorward, Can. J. Phys. 44, 1 (1966)

[25] D.H. Kirkwood, Mater. Sci. Eng. 65, 1 (1984)

[26] V.R. Voller, S. Sundarraj, Mater. Sci. Technol. 9, 6 (1993)

[27] T. Kraft, M. Rettenmayr, H.E. Exner, Model. Simul. Mater. Sci. Eng. 4, 2 (1996)

[28] M. Basaran, Metall. Trans. A 12, 7 (1981)

[29] A. Mortensen, Metall. Trans. A 20, 2 (1989)

[30] D.H. Kirkwood, Mater. Sci. Eng. 73, 1 (1985)

[31] Y. Aoki, S. Hayashi, H. Komatsu, J. Cryst. Growth 123, 1 (1992)

[32] Z. Sun, X. Guo, M. Guo, C. Li, J. Vleugels, Z. Ren, O. Van der Biest, B. Blanpain, J. Phys. Chem. C 116, 33 (2012)

[33] M.E. Glicksman, Principles of Solidification (Springer, New York, 2011), pp. $345-368$

[34] E.C. Kurum, H.B. Dong, J.D. Hunt, Metall. Mater. Trans. A 36, $11(2005)$
[35] H.D. Brody, Dissertation, Massachusetts Institute of Technology, 1965

[36] T.W. Clyne, W. Kurz, Metall. Trans. A 12, 6 (1981)

[37] X. Liu, J. Cui, F. Yu, J. Mater. Sci. 39, 8 (2004)

[38] X. Liu, J. Cui, Y. Guo, X. Wu, J. Zhang, Mater. Lett. 58, 9 (2004)

[39] X. Liu, J. Cui, X. Wu, Y. Guo, J. Zhang, Scr. Mater. 52, 1 (2005)

[40] C. Li, S. He, Y. Fan, H. Engelhardt, S. Jia, W. Xuan, X. Li, Y. Zhong, Z. Ren, Appl. Phys. Lett. 110, 7 (2017)

[41] C. Li, S. He, H. Engelhardt, T. Zhan, W. Xuan, X. Li, Y. Zhong, Z. Ren, M. Rettenmayr, Sci. Rep. 7, 1 (2017)

[42] M.J. Hordon, B.L. Averbach, Acta Metall. 9, 3 (1961)

[43] M. Molotskii, V. Fleurov, Phys. Rev. Lett. 78, 14 (1997)

[44] G.P.P. Pun, Y. Mishin, Acta Mater. 57, 18 (2009)

[45] T.G. Stoebe, H.I. Dawson, Phys. Rev. 166, 3 (1968)

[46] V. Galindo, G. Gerbeth, W. von Ammon, E. Tomzig, J. Virbulis, Energy Convers. Manag. 43, 3 (2002)

[47] A. Mitric, T. Duffar, C.D. Guerra, V. Corregidor, L.C. Alves, C. Garnier, G. Vian, J. Cryst. Growth 287, 2 (2006)

[48] A. Ghofrani, M.H. Dibaei, A.H. Sima, M.B. Shafii, Exp. Therm. Fluid. Sci. 49, 193 (2013) 